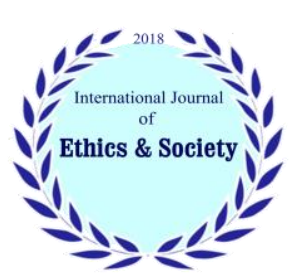

International Journal of Ethics \& Society (IJES)

Journal homepage: $\underline{\text { www.ijethics.com }}$

Vol. 3, No. 3 (2021)

(Original article)

\title{
Bibliometric Analysis of Ethics and Technology Research Based on Google Scholar from 1983 to 2020
}

\author{
Leila Khalili $^{\text {a* }}$, Abulfzal Ghasemzadeh Alishahi ${ }^{b}$ \\ a) Dept of Knowledge \& Information Science, Azarbaijan Shabid Madani University, Tabriz, Iran \\ b) Dept of Educational Sciences, Azarbaijan Shahid Madani University, Tabriz, Iran
}

\section{Abstract}

Background: The aim of the present research is to investigate the research outputs on ethics and technology from the perspective of teachers, based on Google Scholar, from 1983 to 2020.

Methods: This applied and quantitative study used descriptive and bibliometric methods. The population and sample of the study were 1343 documents retrieved from Google Scholar between 1983 and 2020. Harzing's Publish or Perish software was used to collect data. VOSviwer and SPSS software were used respectively for visualizing co-authorship network and statistical cases.

Results: Based on findings, in the first 16 years only 84 documents were published; the number of publications during the next years steadily increased. About $64 \%$ of the papers were written by one author; while only less than $3 \%$ of papers had five or six authors. Also, Spearman correlation test showed that there was a significant and positive association between publication year with Google Scholar rank as well as between publication year and the number of authors per paper. The association between publication year and citation per author and publication year with citation was negative and significant. Furthermore, in the present study, the core authors based on co-authorship network and Collaborative Coefficient (CC) were identified.

Conclusion: In Google Scholar the new published papers are retrieved and placed in the first ranks. The number of citations per author and number of citations in total increased when the year of publication decreased. It seems the number of published papers is not reason enough to receive higher citation.

Keywords: Collaborative Coefficient (CC), Co-authorship networks, Ethics and Technology, Google Scholar

* Corresponding Author: Email: 1.khalili@azaruniv.ac.ir

Received: 17 Jul 2021

Accepted: 25 Aug 2021

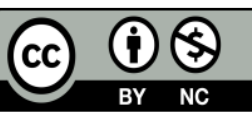

Copyright: (C) 2021 Khalili L. et al. Published by Iranian Association of Ethics in Science and Technology This article is an open access article distributed under a Creative Commons Attribution-Noncommercial 4.0 International License. (https://creativecommons.org/licenses/by-nc/4.0/ ). 


\section{Introduction}

Today, the professional practice is unprofessional without ethics (1). Ethics is an area in philosophy that deals with the aspects of conscientiousness and human behavior (2). Information technology (IT) has become an integral part of our daily life. On the other hand, the role of ethics is consistent in indicating the proper use of technologies and in determining the right direction for the development of human society (3). Every day, society becomes more and more reliant on information and communication technologies. Our innovations seem limitless, as extend their scope to seep into all aspects of people's lives. Application areas such as the internet of things (IoT), cloud computing, social media, artificial intelligence $(\mathrm{AI})$, and big data analytics are usual in enterprise contexts and also in everyday consumer ones (1).

According to James Moor (a scholar in the field of computer ethics) IT is logically malleable, making it one of the most powerful and flexible technologies ever created. IT is a nearly universal tool that can be adjusted and refined to carry out almost any task. The limits of IT, he notes, are essentially the limits of our imagination (4). Rogerson, as a computer ethics professor, explains why ethical considerations are vital at the design stage as society becomes more and more reliant on technology. According to him technology becomes more and more central to our lives; thus, the ethical dimensions ought to become crucial too. He enumerates 'three E's' in technology development: Effectiveness, Efficiency, and Ethics, and emphasizes that these elements should be applied accurately from the start of any program (1).

Ethics and technology, as an interdisciplinary topic, has been studied from different perspectives. For instance, research on interaction between ethics and technology indicated that technology has provided new possibilities for human life and created new ethical questions too. In a sense, "applied ethics" is the product of technological development (5). Also, ethics of technology has been studied in socio-technical systems, which focused on investigating the role of the designer and provides a guide to the product designer. In addition, it was explained that design ethics, as far as possible, should be able to foresee future problems, while addressing current ones (6). Moreover, in the review of literature, some ethical and technological aspects of neuroscience have been studied (7).

Regarding the principles of professional ethics by teachers is one of the most important and essential issues in the education domain (8). On the other hand, the use of information and communication technologies in education can play a crucial role in providing new and innovative forms of support to teachers, students, and the learning process more broadly (9). Therefore, a number of studies that have investigated the ethics and technology from the perspective of teachers could be found with a simple query in Google Scholar or other databases. For instance, the ethical use of IT in higher education among students of medical faculties in the State University of Tetova (Macedonia) indicated that the use of the Internet is significantly high, while the knowledge about the internet ethics is not enough. There was doubt about the patients' privacy, through the health electronic cards as well as the diagnosis of patients' problems, through online consultation; therefore, there was a need to construct a model for teaching and learning through technology (3). Courses on ethics and technology have become compulsory for many students at the three Dutch technical universities during the past few years. In order to deal with these challenges, teachers in ethics at the three technical universities have developed a web-based computer program called Agora. This program enables students to exercise their ethical understanding and skills extensively. The program makes it possible for students to participate actively in moral reflection and reasoning, and to develop the moral competencies that are needed in their later professional practice (10). However, IT continues to integrate into the educational process and is increasingly becoming an integral part of the education system (3). It is increasingly demanded that science and technology courses include an ethics teaching component 
which will help students to address ethical issues (11).

The ethics of science and technology requires a lot of empirical and descriptive research in various fields (12); therefore, researchers in different subject areas should carry out researches regarding ethics and technology, based on their perception. Bibliometric analysis is one of the most commonly used methods in the evaluation of researchers' performance and the evaluation of research outputs. A bibliometric analysis of research outputs on ethics and technology from the perspective of teachers will indicate an overview of this research in terms of features such as co-authorship network, co-authorship pattern, publication year and number of citations.

On the other hand, researchers do their research alone or in collaboration with other researchers. Although there is a tendency toward collaboration in doing research and publishing, co-authorship pattern is different in research areas. A rise was reported in the average number of authors, share of co-authorship and international co-authored papers in the most subject area in social science during 1980-2013 (13). Also, in a bibliometric analysis of worldwide coronavirus research it was found that only 6.53 percent of documents had one author (14).

Collaborative Coefficient (CC) is a measure of collaborative strength in a discipline that has a value between 0 and 1 ; when the value tends toward zero, it means single-authored papers dominate. In a study on the co-authorship patterns in economics, it was found that the CC is 0.38 ; also, the CC has risen from 0.31 in 2000 to 0.41 in 2014 (15). Likewise in study of collaborative authorship trend in Indian LIS journals it was reported that the CC quantity was 0.366 (16). Furthermore, in a research study based on Web of Science (WOS) data, it was found that the CC value for Iranian co-authorship networks in psychology, management, economics and library and information science was 0.59, 0.53, 0.51 and 0.4 respectively (17). On the other hand, the results of a study indicated that the CC of Iranian researchers in the field of pharmacy and pharmacology in WOS during 2000-2012 was 0.7, relatively high CC in comparison to social science (18).
Bibliometric studies generally use WOS and Scopus for data gathering; Google Scholar, like mentioned databases, can be used in bibliometric studies. An investigation indicated that Google Scholar covers more publications and citations than WOS and Scopus. It was concluded that Google Scholar is an alternative tool for evaluating research (19).

Given the need for study in this area, importance of bibliometric studies, and significant role of Google Scholar among researchers, the present study aims to carry out a bibliometric analysis of ethics and technology research based on Google Scholar since 1983-2020. The studied research samples are mainly from the viewpoint of teachers. In order to achieve the main goal of the research, following sub-objectives are posed.

- To report the features of research outputs in terms of publication year and type

- To identify the co-authorship pattern and CC for authors

- To visualize and analyze the co-authorship network among authors

- To identify the association between the publication year with Google Scholar Rank, number of authors per paper, citation per author, and total citation

- To identify the association between total link strength with documents and citation

- To announce top 10 core authors based on the number of documents, citation and total link strength.

\section{Material \& Methods}

This applied and quantitative study used descriptive and bibliometric methods. Population and sample of the study was 1343 documents retrieved with the keywords "ethics \& technology teachers face" in Google Scholar between 1983 and 2020. Search process in Google Scholar started with a query "Ethics and Technology * teachers"; in next stage the expression "ethics and technology teachers face" that was offered by Google Scholar, is selected from the related list and is chosen as the topic of study. In order to mine the data with the mentioned expression in Google Scholar, Harzing's 
Publish or Perish was used and collected data was merged for further analysis. Data gathering was carried out on March $12^{\text {th }}, 2021$.

In the present study the effect size of Correlation Coefficient is computed. The value of the effect size of the $r$ correlation ranges between -1 to +1 . Three classes are identified for effect size, small size if the value of $r$ varies around 0.1 , medium size if $r$ varies around 0.3 , and large size if $\mathrm{r}$ varies more than 0.5 (20). Also, the formula created by Ajiferuke et al., (1988) was used to compute the CC (21). Descriptive and Inferential statistics, as well as co-authorship network analysis, were used to answer the research questions. VOS viewer and SPSS software were used for visualizing co-authorship network and statistical cases respectively.

\section{Results}

\section{Descriptive Information about Study Popula- tion}

In this section descriptive statistics for the year of publication and type of documents are presented. Out of 1343 documents only 1226 cases had publishing year, and the publishing year for 117 documents was not found in extracted data. During 1983 until 1999 only 84 documents were published. Number of published documents in the period of 2000-2005, 2006-2010, 2011-2015 and 2016-2020 were 144, 253, 340 and 405 documents respectively. The data indicated a growth rate in the number of publications in recent years (Figure 1).

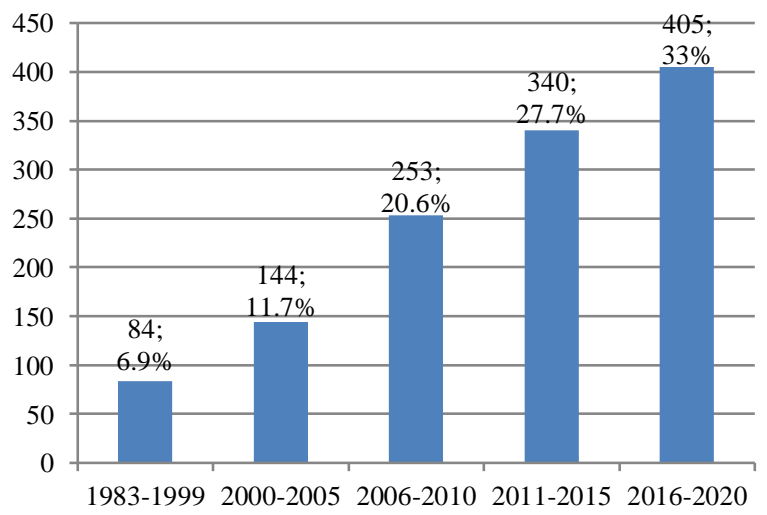

Fig 1. Year of publication
Out of 1343 retrieved documents, about 22.8\% were Portable Document Format (pdf), 14.3\% book, $9.1 \%$ citation, $2.5 \% \mathrm{html}$ and $0.3 \%$ was in doc format. The format of a majority of $51 \%$ was not defined; most of undefined documents are in the databases that require access fees (Figure 2).

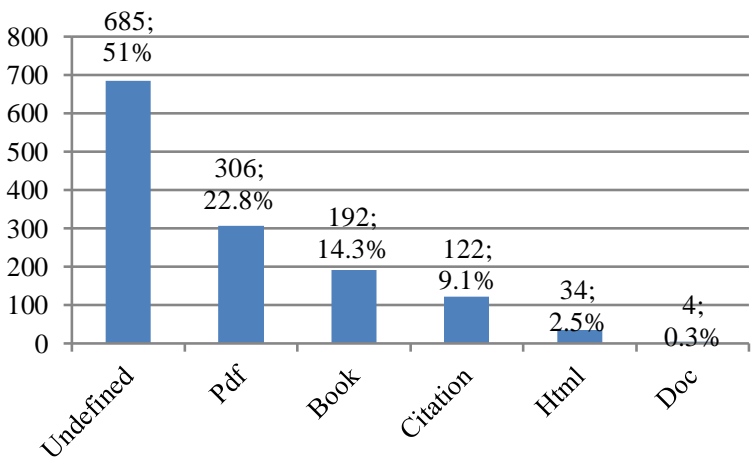

Fig 2. Type of retrieved documents

Co-authorship Pattern and Collaborative Coefficient (CC)

Figure 3 indicates co-authorship pattern of ethics and technology teachers face research. A large majority $(64 \%)$ of papers were written by one author; while only less than $3 \%$ of papers had five or six authors. Also $19.9 \%$ of papers had two authors, $8.9 \%$ three authors and $4.7 \%$ four authors. The mean of co-authorship is 1.62 ; it means that each document is co-authored by 1.62 authors (Figure 3). Furthermore, the value for $\mathrm{CC}$ of the researchers was 0.21 , a sign of a single author's tendency in this domain.

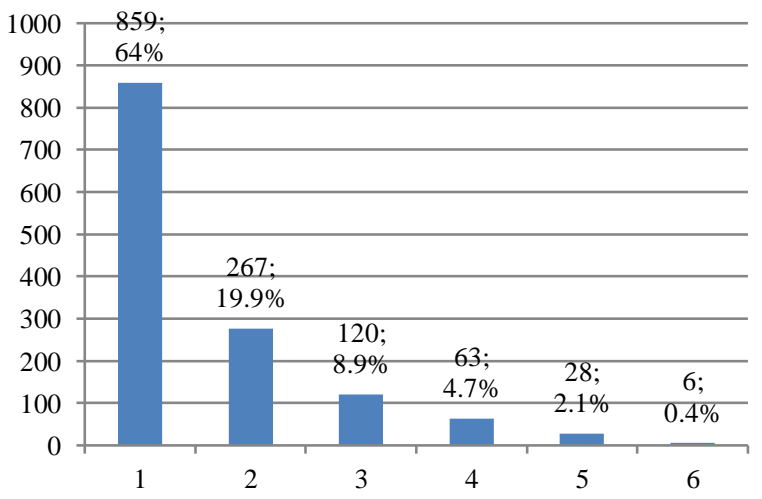

Fig 3. Co-authorship pattern 


\section{Association between Indicators}

In order to distinguish the relationship between indicators, Spearman correlation test was carried out. Findings indicate that there was a significant and positive association between the year of publication and Google Scholar rank as well as year of publica- tion with number of authors per paper. The association between year of publication with citation per author, and year of publication with citation was negative and significant. The effect size of Spearman test only for the year of publication and Google Scholar rank was in medium level; the effect size for the rest of tests was small (Table 1).

Table 1. Spearman Correlation Test

\begin{tabular}{|c|c|c|c|}
\hline \multicolumn{1}{|c|}{ Association between } & Correlation Coefficient & Sig. (2-tailed) & Effect size \\
\hline Publication year \& Google Scholar rank & $.337^{* *}$ & .000 & Medium \\
\hline Publication year \& number of authors per paper & $.097^{* *}$ & .001 & Small \\
\hline Publication year \& citation per author & & & Small \\
\hline Publication year \& total citation & $-.243^{* *}$ & .000 & Small \\
\hline
\end{tabular}

\section{Co-authorship Network of Researchers}

1343 retrieved documents had 1810 authors. Due to high number of authors, VOS viewer by default considered 1000 authors for co-authorship network; in order to do this, for each 1810 authors, the total strength of the co-authorship links with other authors were computed by software and the authors with the greatest total link strength were selected for co-authorship network. The total link strength shows the total strength of a certain author's co-authorship links with other authors (22).
Co-authorship network with 1000 authors had 381 cluster and 953 links. Also, the total link strength of this network was 1014. Authors in red area and with large font size in graph are the core authors (nodes) of the network based on number of publications. As seen the authors like Poel, Ess, Tavani and others in red area and large label have the highest number of publications in the co-authorship network (Figure 4).

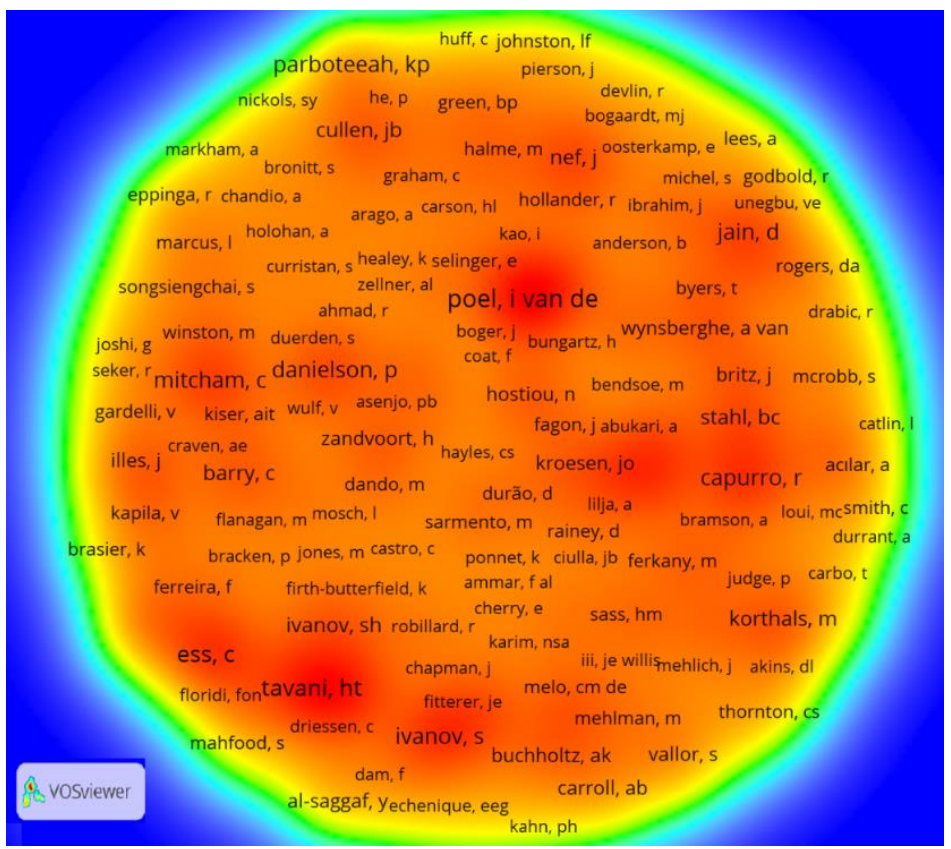

Fig 4. Co-authorship network with 1000 authors 
Also, the largest connected network of 1810 authors consisted of 28 authors with 9 clusters, 46 links and total link strength of 50. Each cluster has a different color (Figure 5).

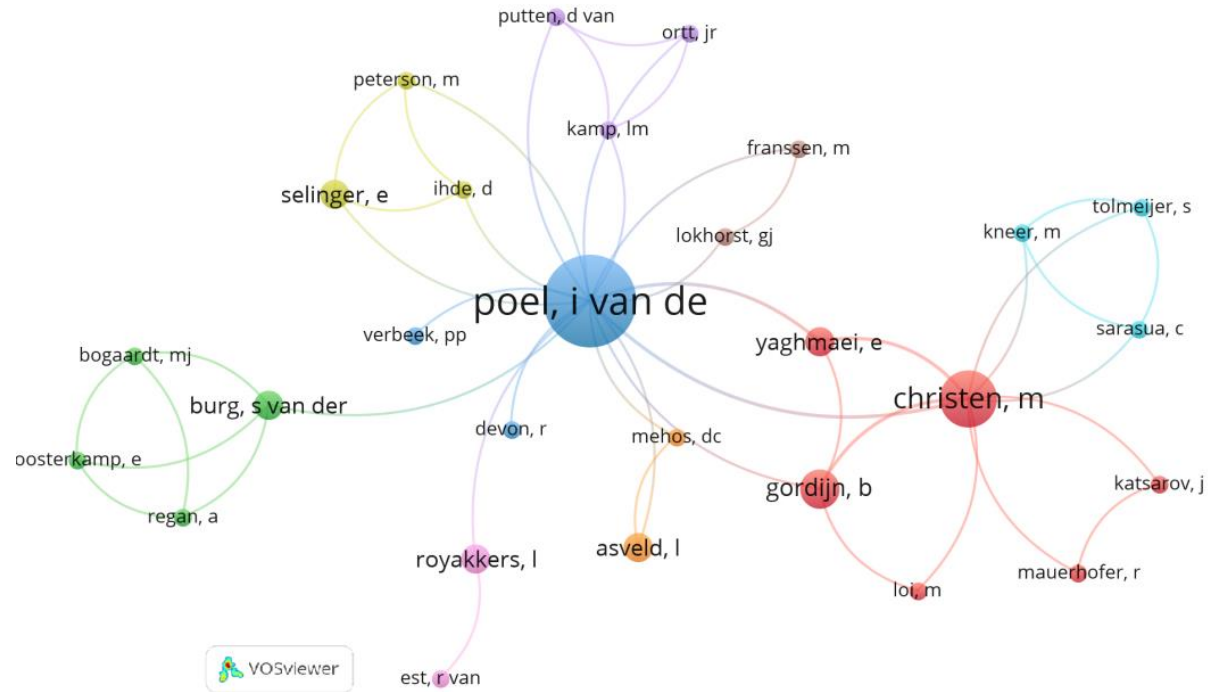

Fig 5. The largest connected co-authorship network with 28 authors

Table 2 indicates the names of top 10 authors in terms of number of documents, number of citations and total link strength. The author by name of Poel is placed in the first rank based on number of documents and total link strength; however, this author has received 606 citations and therefore was not among top 10 authors based on number of citations. On the other hand, Buchholtz and Carroll, with three documents, and Douglas, with two documents, had the highest number of citations among authors. Christen and Webster, based on total link strength and number of documents, were among top 10 . It should be noted that authors with five documents were six cases and, in the table, only names of three of them have been mentioned. Also, it should be noted that in total, $603(33.3 \%)$ of authors had no citation.

Table 2. Core authors

\begin{tabular}{|l|c|l|c|l|c|}
\hline Author & N. of Doc. & author & N. of Citation & Author & Total link strength \\
\hline Poel, I van de & 10 & Buchholtz, AK & 5918 & Poel, I van de & 19 \\
\hline Ess, C & 7 & Carroll, AB & 5918 & Christen, M & 12 \\
\hline Tavani, HT & 7 & Douglas, DG & 4629 & Webster, C & 9 \\
\hline Webster, C & 7 & Brunsveld, N & 2614 & Ivanov, S & 9 \\
\hline Capurro, R & 6 & Jr, jf hair & 2614 & Stahl, BC & 9 \\
\hline Ivanov, S & 6 & Page, M & 2614 & Bassani, C & 8 \\
\hline Mitcham, C & 6 & Barrington, I & 1194 & Calisgan, E & 8 \\
\hline Christen, M & 5 & Casner-lotto, J & 1194 & Ferreira, F & 8 \\
\hline Cotton, M & 5 & Barbour, IG & 1007 & Moon, AJ & 8 \\
\hline Danielson, P & 5 & Heyl, BS & 953 & Operto, F & 8 \\
\hline
\end{tabular}

Moreover figure 6 indicates the co-authorship network based on number of received citations. As seen in the figure Buchholtz, Carroll and Douglas are the top three key authors with the highest 
number of citations in the co-authorship network. The size and color of the label represents the counts of co-citations.

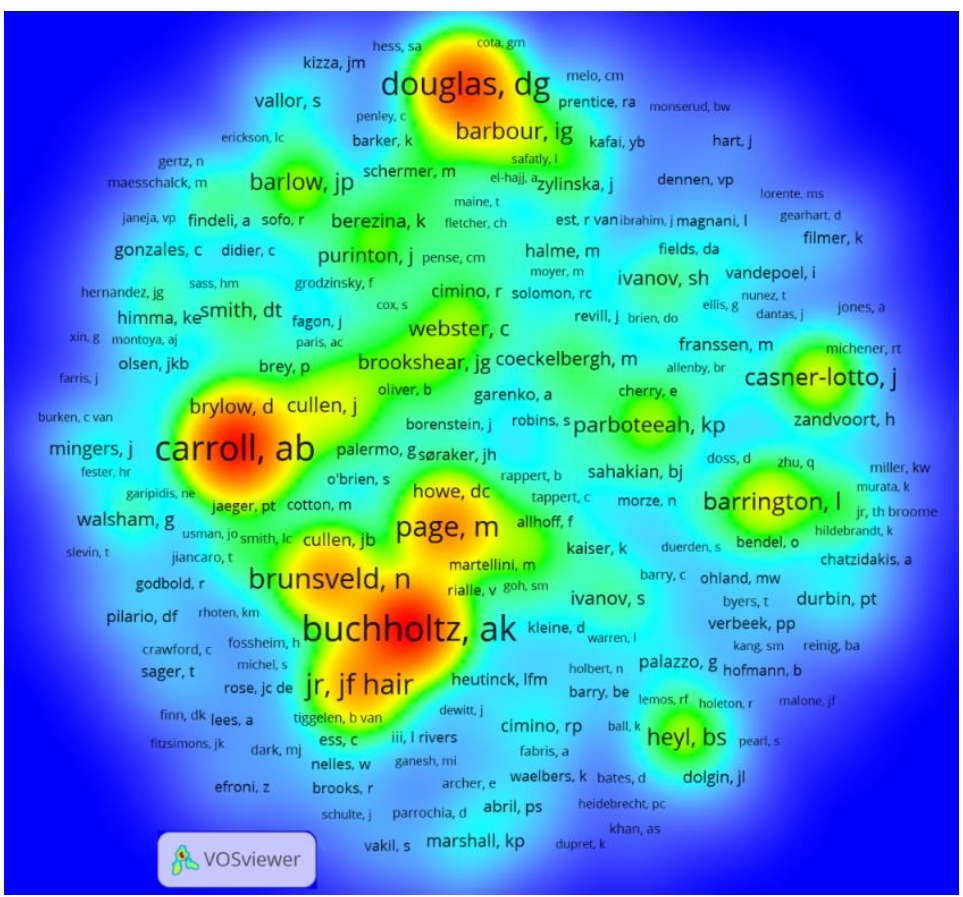

Fig 6. Co-authorship network based on number of citations

In order to know whether there any relation between total link strength with documents and citation, Spearman correlation test was used. The results are presented in table 3. Based on Spearman test, there was a positive and significant association between mentioned indicators. Also, the effect size of the tests is small.

Table 3. Spearman Correlation Test

\begin{tabular}{|c|c|c|c|}
\hline Association between & Correlation Coefficient & Sig. (2-tailed) & Effect size \\
\hline Total link strength \& documents & $.197^{* *}$ & .000 & Small \\
\hline Total link strength \& citation & $.180^{* *}$ & .000 & Small \\
\hline
\end{tabular}

\section{Discussion}

The aim of the present study is to study the ethics and technology (teacher face) research based on Google Scholar since 1983-2020 using bibliometric analysis. During 37 years 1343 documents were published in this area. In the first 16 years only 84 were published; the number of publications during next year's steadily increased in a way that the number of documents in the last five years is almost five times more than the first 16 years. In recent years, however, the number of publications in all domains increased. Pdf was the major format of the documents; however, about half of the documents were categorized as undefined; this means these documents are accessible only through subscription databases.

A large majority of papers were written by one author; in other words, the co-authorship pattern in this area was single author and a few percent of papers had five or six authors. However, the result of Spearman correlation test indicates that there was a significant and positive association between publication years and the number of authors per 
paper. It means the number of authors per paper increased during current years. Considering the increasing number of authors per paper in recent years, prior studies reported a rise in the average number of authors in the most subject areas in social science (13); also, a large majority of publication on coronavirus research had more than one author (14). However, due to the nature of each subject area, the number of authors per paper in various domains is different.

Also based on CC value (0.21), the authors had tendency to work alone. This finding is in line with the findings of the previous studies which reported that the CC in economics area was 0.38 (15); the CC for co-authorship network of Indian LIS journals was 0.366 (16); the CC value for Iranian co-authorship networks in psychology, management, economics and library and information science was $0.59,0.53,0.51$ and 0.4 respectively (17); while the CC of Iranian researchers in the field of pharmacy and pharmacology in WOS was 0.7 (18); it seems the CC quantity in pharmacy domain is relatively high in comparison to social science.

Also, Spearman correlation test illustrates that there was significant and positive association between publication years and Google Scholar rank; it means in Google Scholar the new published papers are retrieved and placed in the first ranks. On the other hand, the association between the year of publication with citation per author, and the year of publication with citation was negative and significant. This means that the number of citations per author and the number of citations in total increases when year of publication decreases.

In current study the core authors based on co-authorship network were identified. Based on the number of documents and total link strength, Poel as a core and key author was placed in the first rank; however, this author, despite receiving good number of citations, was not among the top 10 authors based on the number of citations. On the other hand, Buchholtz and Carroll, with three documents, and Douglas, with two documents, had the highest number of citations among the authors. It seems the number of published papers is not reason enough to allow a researcher to receive higher citation. Based on Spearman correlation test, the number of documents and citations had positive effect on total link strength; however, the influence of publication number was a little bit more than citation number.

\section{Conclusion}

The number of publications in the last five years is almost five times more than the first 16 years. The co-authorship pattern in this study was single author and also the quantity of CC indicated the dominance of single-authored papers; however, the number of authors per paper increased during recent years. Furthermore, it can be concluded that co-authorship pattern and CC is different in the various fields and even sub-fields. Usually in Google Scholar the newly published papers are retrieved and placed in the first ranks; also, the older papers have more citations. Even though the quantity of published papers is appreciated in the scientific community, the number of received citation is more appreciated due to the quality of work and being considered as a hot reference source. The influence of document number on total link strength in comparison with citation number is slightly more.

\section{Ethical Consideration}

Moral issues (such as plagiarism, misleading, making and or forging data, publishing or sending to two places, redundancy and etc.) have been fully considered by the writers.

\section{Conflict of Interest}

The authors declare that there is no conflict of interests.

\section{References}

1. Rogerson S (2017). Coding ethics into technology. Hack \& Craft News, Additional reporting by Chris Middleton. Available at: http://hncnews.com/coding-ethics-technology. Accessed: 24 April 2021. 
2. Farhud DD (2019). Epigenetic and Ethics: How are Ethical Traits Inherited? International Joumal of Ethics \& Society (IJES), 1 (3):14.

3. Hamiti, M, Reka B, Baloghová A (2014). Ethical use of information technology in high education. Procedia-Social and Behavioral Sciences, 116: 4411-4415. Doi: https://doi.org/10.1016/j.sbspro.2014.01.957

4. Bynum TW (2013). Rethinking the foundations of philosophy in the information age. in crossing boundaries: ethics in interdisciplinary and intellectual relations. ACM SIGCAS Computers and Society, 43(1):6-8. Doi: https://doi.org/10.1145/2505414.2505415

5. Shakib J, Layton D (2014). Interaction between ethics and technology. In: 2014 International Symposium on Ethics in Science, Technology and Engineering. IEEE, USA.

6. Fiore $\mathrm{E}$ (2020). Ethics of technology and design ethics in socio-technical systems: Investigating the role of the designer. Available at: https://joumals.oslometno/index.php/formakademisk/about. Accessed: 12 April 2021. Doi: https://doi.org/10.7577/formakademisk.2201

7. Shukla VK, Guha A (2013). The ethical and technological aspects: neuroscience. Available at: https://www.researchgate.net/profile/Vinod-Shukla/publication/315669480 The Ethical and Technological Aspects Neurosci-

ence/links/58da2a80a6fdccca1c4c0bfc/The-Ethicaland-Technological-Aspects-Neuroscience.pdf. Accessed: 12 April 2021.

8. Shakeri M, Pakzaban F, Tavalaei M (2020). Designing a professional ethics model for primary teachers in Yazd. International Journal of Ethics \& Society (IJES), 2 (2):19-27.

9. The World Bank (2020). Digital technologies in education. Available at https://www.worldbank.org/en/topic/edutech. Accessed: 29 April 2021.

10. Van der Burg S, Van de Poel I (2005). Teaching ethics and technology with Agora, an electronic tool. SCI ENG ETHICS, 11: 277-297.https://doi.org/10.1007/s11948005-0046-8

11. Crosthwaite J (2001). Teaching ethics and technology what is required? Science \& Education, 10:97-105. https://doi.org/10.1023/A:1008757414097

12. Chaparak A, Mousavi A, Alasti K (2019). What is ethics of science and technology? Ethics in Science and Technology, 14
(3): 1-6. (In Persian). Dor: http://dorl.net/dor/20.1001.1.22517634.1398.14.3.1.4

13. Henriksen D (2016). The rise in co-authorship in the social sciences (1980-2013). Scientometrics, 107(2): 455-476. Doi: https://doi.org/10.1007/s11192-016-1849-x

14. Khalili L, Sreekumar MG (2020). Bibliometric analysis of worldwide coronavirus research based on web of science between 1970 and February 2020. International Journal of Information Science and Management (IJISM), 19(1): 2743.

15. Biradar N, Tadasad PG (2016). Authorship pattern and collaborative research in economics. Pearl: A Journal of $L i$ brary and Information Science, 10(1): 45-51. Doi: http://dx.doi.org/10.5958/0975-6922.2016.00006.1

16. Mondal D, Jana S (2018). Collaborative authorship trend in leading Indian LIS joumals. DESIDOC Joumal of Library \& Information Technology, 38(5): $320 . \quad$ Doi: https://doi.org/10.14429/dilit.38.5.12917

17. Nikzad M, Jamali HR, Hariri N (2011). Patterns of Iranian co-authorship networks in social sciences: A comparative study. Library \& Information Science Researh, 33(4): 313-319. Doi: https://doi.org/10.1016/j.lisr.2011.01.005

18. Osareh F, Serati Shirazi M, Khademi R (2014). A Survey on co-authorship network of iranian researchers in the field of pharmacy and pharmacology in web of science during 2000-2012. Journal of Health Administration, 17(56): 33-45.

19. Ocholla D, Onyancha OB (2009). Assessing researchers' performance in developing countries: is Google Scholar an altemative? Mousaion, 27 (1): 43-64. Available at: http://uir.unisa.ac.za/bitstream/handle $/ 10500 / 5269 /$ Onyancha $\% 20 \& \% 20$ Ocholla Assessing $\% 20$ Researchers $\% 20$ Performance.pdf?sequence=1. Accessed: 17 April 2021.

20. Cohen J (1988). Statistical power analysis for the behavioral sciences. $2^{\text {nd }}$ ed. Hillsdale, NJ: Erlbaum.

21. Ajiferuke I, Burell Q, Tague J (1988). Collaborative coefficient: A single measure of the degree of collaboration in research. Scientometrics, 14 (5): 421-433. Doi: https://doi.org/10.1007/BF02017100

22. Waltman L, Van Eck N (2017). VOSviewer Manual. Available at: https://www.vosviewer.com/documentation/Manual VOSviewer 1.6.6.pdf. Accessed: 7 April 2021. 